\title{
Species and Strain-specific Typing of Cryptosporidium Parasites in Clinical and Environmental Samples
}

\author{
Lihua Xiao/ ${ }^{+}$, Irshad Sulaiman, Ronald Fayer*, Altaf A Lal
}

\begin{abstract}
Division of Parasitic Diseases, National Center for Infectious Diseases, Centers for Disease Control and Prevention, US Department of Health and Human Services, Atlanta, GA 30341 *Parasite Immunobiology Laboratory,

Agriculture Research Service, U.S. Department of Agriculture, Beltsville, MD 20705, USA
\end{abstract}

Cryptosporidiosis has recently attracted attention as an emerging waterborne and foodborne disease as well as an opportunistic infection in HIV infected individuals. The lack of genetic information, however, has resulted in confusion in the taxonomy of Cryptosporidium parasites and in the development of molecular tools for the identification and typing of oocysts in environmental samples. Phylogenetic analysis of the small subunit ribosomal RNA (SSU rRNA) gene has shown that the genus Cryptosporidium comprises several distinct species. Our data show the presence of at least four species: C. parvum, C. muris, C. baileyi and C. serpentis (C. meleagridis, C. nasorum and C. felis were not studied). Within each species, there is some sequence variation. Thus, various genotypes (genotype 1, genotype 2, guinea pig genotype, monkey genotype and koala genotype, etc.) of $\mathrm{C}$. parvum differ from each other in six regions of the SSU rRNA gene. Information on polymorphism in Cryptosporidium parasites has been used in the development of species and strain-specific diagnostic tools. Use of these tools in the characterization of oocysts in various samples indicates that $\mathrm{C}$. parvum genotype 1 is the strain responsible for most human Cryptosporidium infections. In contrast, genotype 2 is probably one of the major sources for environmental contamination, and has been found in most oysters examined from Chesapeake Bay that may serve as biologic monitors of estuarine waters.

Key words: Cryptosporidium - phylogeny - genotype - ribosomal RNA

Cryptosporidiosis is a coccidian infection of humans, domestic animals and other vertebrates. In young farm animals, especially preweaned dairy calves, it causes a severe enteritis resulting in significant morbidity, mortality and economic loss. In humans, it results in an acute infection of the digestive system in immunocompetent individuals, and chronic, life-threatening disease in immunocompromised patients. Several transmission routes, including person-to-person, contamination of water or food, and zoonotic infection, are possible. The specific source of Cryptosporidium oocysts involved in infection or contamination is frequently unknown, largely due to a lack of detailed epidemiologic investigation and strain-typing tools. The latter results from a

This work was supported in part by inter-agency agreements (\#DW75937730-01-0 and DW7593784-01-0) from CDC and EPA, and Emerging Infectious Diseases and Opportunistic Infectious Diseases funds from CDC, USA.

${ }^{+}$Corresponding author. Fax: +770-488-4454.

Received 15 June 1998

Accepted 30 July 1998 current paucity of molecular characterization and lack of acceptance of the taxonomy of Cryptosporidium species and genotypes.

\section{CRYPTOSPORIDIUM SPECIES}

Since the discovery of Cryptosporidium muris and $C$. parvum in rodents, over 20 Cryptosporidium species have been described in various animal hosts (O'Donoghue 1995). Species were named based on the historical belief that Cryptosporidium spp. are coccidian parasites, and therefore share the strict host specificity demonstarted by many other coccidian parasites. Studies conducted in late 1970s and early 1980s, however, indicated that some isolates of Cryptosporidium were infectious for several animal species. Thus, one group of investigators suggested that all Cryptosoridium parasites were the same species, $C$. muris (Tzipori et al. 1980). Others demonstrated that host specificity was present among isolates from different classes of vertebrates (O'Donoghue 1995). Based on these observations, Levine $(1984,1986)$ classified the parasites from mammals, birds, reptiles and fish as $C$. muris, $C$. meleagridis, $C$. serpentis, and $C$. nasorum, respectively. Subsequent studies demonstrated that $C$. parvum from mammals and $C$. baileyi from birds were biologically and morphologically different from C. muris and C. meleagridis 
(Upton \& Current 1985, Current et al. 1986). Thus, C. parvum, C. muris, C. baileyi, C. meleagridis, C. serpentis and C. nasorum were considered valid Cryptosporidium species (O'Donoghue 1995). More recently, based on published reports of host specificity, Fayer et al. (1997) added C. felis from cats and $C$. wrairi from guinea pigs to the list of valid species, whereas Tzipori and Griffiths (1998)suggested that current evidence does not support the concept that there is more than one species of Cryptosporidium parasites.

The lack of genetic information and the presence of erroneous sequences in a few published studies have added to the present state of taxonomic confusion. Cai et al. (1992) compared the small subunit (SSU) ribosomal RNA (rRNA) gene, and showed a greater than $99 \%$ identity between one C. parvum and one C. muris isolate. Alignment of sequences (accession numbers X64430 to 64343) from that study with sequences from us and others indicates that all four sequences from Cai et al. (1992) are the C. muris type. Minor sequence errors (one insertion and 12 deletions of nucleotides) were found in the SSU rRNA sequence (L25642) of another published study (Kilani \& Wenman 1994). These sequences and five other sequences deposited in the GenBank were used recently by Tzipori and Griffiths (1998) in a phylogenetic analysis of Cryptosporidium parasites. Based on this analysis, they concluded that the observed inter-species and intra-species variation did not favor the designation of separate Cryptosporidium species, and therefore all Cryptosporidium oocysts, including those from lower vertebrates, should be considered hazardous to humans.

We have recently sequenced the SSU rRNA genes from various isolates of C. parvum, C. muris, $C$. baileyi and $C$. serpentis, and used these sequences in a phylogenetic analysis (Xiao et al. unpub. data). Results of the analysis indicate that Cryptosporidium parasites are a multi-species complex containing at least four species: $C$. parvum, $C$. baileyi, C. muris and C. serpentis (C. felis, $C$. nasorum and $C$. meleagridis were not studied). The evolutionary distance between the Cryptosporidium guinea pig isolate and C. parvum is too small to warrant a separate species designation.

\section{CRYPTOSPORIDIUM PARVUM GENOTYPES}

Results of various studies indicate that there is variation within the species $C$. parvum. Two dimensional gel electrophoresis has revealed minor differences between human and bovine $C$. parvum isolates (Mead et al. 1990), which has been confirmed by immunoblot (Nichols et al. 1991, Nina et al. 1992), isozyme (Ogunkolade et al. 1993,
Awad-El-Kariem et al. 1995), and restriction fragment length polymorphism (RFLP) analysis (Ortega et al. 1991). More recently, random amplified polymorphic DNA (RAPD) markers have revealed two distinct groups of human $C$. parvum isolates, one containing most human isolates and the other containing some human isolates and all animal isolates (Morgan et al. 1995), indicating the possibility of zoonotic infection. Similar results have been obtained by sequence data or PCR-RFLP analysis of a repetitive sequence (Bonnin et al. 1996), bifunctional dihydrofolate reductase thymidylate synthase (DHFR) (Vasquez et al 1996), rRNA repeats (Carraway et al. 1996), polythreonine motifs (Carraway et al. 1997), oocyst wall protein (COWP) gene (Spano et al. 1997), and thrombospondin anonymous protein-2 (TRAPC2) gene (Peng et al. 1997 Sulaiman et al. unpub. data). It remains unclear, however, whether the same two genotypes are present in all these polymorphic loci. Results of our multi-locus analysis suggest that indeed the same genotypes are linked across all polymorphic genes (SSU rRNA, TRAP$\mathrm{C} 1$, TRAP-C2, CP15, and B-tubulin intron) examined (Xiao et al. unpub. data).

Our phylogenetic analyses of the SSU rRNA gene have revealed diversities in $C$. parvum not previously observed (Table I). Human $C$. parvum isolates differ from bovine isolates in four regions of the SSU rRNA gene. Likewise, the Cryptosporidium isolate from guinea pigs $(C$. wrairi) also differs from the bovine isolates in four regions, two of which are the same polymorphic regions between the human and bovine genotypes, thus representing a third genotype of $C$. parvum. Partial sequences obtained from a monkey by us and from a koala by Morgan et al.(1997) indicate the presence of two additional genotypes. The difference between the human and bovine genotypes in nucleotides 689-699 has also been observed recently by Morgan et al. (1997). We, however, have observed that some human isolates have the sequence TTTTTT instead of TTTTTTTTTTT. Based on a partial SSU rRNA gene sequence, another group also identified a new C. parvum genotype (Carraway et al. 1994, 1996). The new genotype sequence (ICP), however, is identical to the C. muris bovine isolate (Xiao et al. unpub. data).

\section{CRYPTOSPORIDIUM GENOTYPES IN CLINICAL} SAMPLES

Results of the molecular characterization have been used by us in the development of molecular diagnostic tools. A PCR-RFLP technique based on the polymorphism in the TRAP-C2 gene was developed and used in the analysis of human clinical samples from various outbreak and non-outbreak cases (Sulaiman et al., unpub. data). Results of our 
TABLE I

Differences among genotypes of Cryptosporidium parvum in the SSU rRNA gene

\begin{tabular}{lllllll}
\hline & \multicolumn{5}{c}{ Location of mutations in the SSU rRNA gene $^{a}$} \\
\cline { 2 - 7 } Genotype & $129-135$ & $179-184$ & $262-267$ & $639-656$ & $689-699$ & $795-800$ \\
\hline 1 & TTTTACT & AAACTC & AATTAA & AAAATATTTTGATGAATA & $\begin{array}{l}\text { TTTTTTTTTTT } \\
\text { or TTTTTT }\end{array}$ & TTTTT \\
2 & TTT-ACT & AAACTC & ATTAAA & AAAATATTTTGATGAATA & TATATTTT & TTTCTT \\
wrairi & TTT-ACT & AGGCCC & ATAAAT & ATAATATTTTGAA-AATA & TATATTTTT & TTTCTT \\
Monkey & unknown & unknown & AATTAA & AATATATTTTGATGAATA & TTTTTTTTT & TTTTTT \\
Koala & unknown & unknown & unknown & ATTATACTTTTTAAGGTG & TATTTTTTT & unknown \\
\hline
\end{tabular}

$a$ : nucleotide positions in the aligned sequences of all Cryptosporidium species. Actual positions in individual sequences may vary slightly due to the introduction of gaps in the aligned sequences (1757 bp); $b$ : based on the sequence by Morgan et al. (1997).

studies and those by others (Table II) indicate that anthroponotic organisms account for the majority of the cases and person-to-person transmission is likely to be an important transmission route of cryptosporidiosis in non-outbreak cases. This is evident from the large number of genotype 1 parasites in sporadic cases and HIV patients (Sulaiman et al., unpub. data). This is in agreement with some recent observations by others (Table II). Even in outbreak cases, many cryptosporidiosis outbreaks are caused by anthroponotic (genotype 1) parasites (such as the waterborne outbreaks in Milwaukee in 1993, Nevada in 1994, and Florida in 1995; the Atlanta day care outbreak in 1995, and the Washington outbreak in 1997). It is possible that genotype 2 parasites largely cause human infection through contamination of water or food or direct contact with infected animals, especially in rural areas. Examples are the Maine apple cider outbreak in 1993, the British Columbia waterborne outbreak in 1996, and the Pennsylvania multi-family outbreak in 1997 . The reason for the high percentage of genotype 2 in AIDS patients (6/13 patients) in France (Bonnin et al. 1996) is not clear. Taken together, there are two distinct populations of $C$. parvum parasites, one cycling only in humans and one cycling predominantly in animals. The latter can cause human infections.

\section{CRYPTOSPORIDIUM PARASITES IN ENVIRONMEN- TAL SAMPLES}

One difficulty facing the investigation of waterborne outbreaks of cryptosporidiosis is the lack of a sensitive, specific diagnostic tool. Most of the current PCR diagnostic and genotyping tools are designed for analysis of clinical samples. Because they cannot differentiate Cryptosporidium species and have low sensitivities, they have limitations in the analysis of water samples. Two PCR-RFLP techniques based on the SSU rRNA gene have claimed to differentiate $C$. parvum from other Cryptosporidium parasites (Awad-El-Kariem et al. 1994, Leng et al. 1996). One technique (Leng et al. 1996) used conserved sequences for primers and therefore amplify the SSU rRNA gene of all eukaryotic organisms. The other technique (AwadEl-Kariem et al. 1994) used erroneous sequence by Cai et al. (1992) as primers, reducing the efficiency of amplification and making interpretation of the data difficult. Nor have the present genotyping techniques been subjected to cross-species testing, making interpretation of results from environmental samples that could contain nonparvum Cryptosporidium virtually impossible.

Based on sequence information on the SSU rRNA gene, we have developed a PCR-RFLP technique for both species identification and genotyping of Cryptosporidium parasites. Because the technique employs nested PCR and targets the multi-copied rRNA gene, it has sufficient sensitivity for use in environmental samples. We have used this technique in the analysis of Cryptosporidium oocysts recovered from the gill washings and hemolymph of oysters (Crassostrea virginica) collected from the Chesapeake Bay. We are interested in oysters because they are filter feeders that concentrate and accumulate Cryptosporidium oocysts they have removed from surface waters. The use of oysters enables investigators to avoid the poor recovery rate often associated with filtering hundreds of liters of water to determine the presence or absence of Cryptosporidium oocysts. Before applying our technique Cryptosporidium oocysts were morphologically identified in oysters, but the species of most of the oocysts was unconfirmed (Fayer et al. 1998). 
TABLE II

Prevalence of genotype 2 in human clinical samples reported in various studies

\begin{tabular}{|c|c|c|c|c|c|}
\hline Location & Sample source & $\begin{array}{c}\text { \# of } \\
\text { samples }\end{array}$ & $\begin{array}{c}\text { genotypes } \\
1 / 2 \\
\end{array}$ & $\begin{array}{l}\text { Technique } \\
\text { used }\end{array}$ & Reference \\
\hline England \& Guinea Bissau & Sporadic cases & 11 & $10 / 1$ & Isozyme & Awad-El-Kariem et al. 1995 \\
\hline Western \& South Australia & Sporadic cases & 14 & $12 / 2$ & RAPD & Morgan et al. 1995 \\
\hline USA & Sporadic cases & 3 & $2 / 1$ & $\begin{array}{l}\text { ITS1 and SSU } \\
\text { rRNA repeat }\end{array}$ & Carraway et al. 1996 \\
\hline Northeast France & $\mathrm{HIV}+$ patients & 13 & $6 / 7$ & $\begin{array}{l}\text { PCR-RFLP of } \\
\text { repetitive DNA }\end{array}$ & Bonnin et al. 1996 \\
\hline UK & Sporadic cases & 7 & $5 / 2$ & $\begin{array}{l}\text { PCR-RFLP } \\
\text { of oocyst wall } \\
\text { protein }\end{array}$ & Spano et al. 1997 \\
\hline Western Australia & Sporadic cases & 32 & $28 / 4$ & $\begin{array}{l}\text { PCR of RAPD } \\
\text { fragment }\end{array}$ & Morgan et al., 1997 \\
\hline USA \& Canada & $\begin{array}{l}\text { Outbreaks \& } \\
\text { sporadic cases }\end{array}$ & 16 & $13 / 3$ & $\begin{array}{l}\text { TRAP-C2 } \\
\text { sequencing }\end{array}$ & Peng et al. 1997 \\
\hline $\begin{array}{l}\text { USA, Canada, India } \\
\text { \& Guatemala }\end{array}$ & $\begin{array}{l}\text { Outbreaks \& } \\
\text { sporadic cases }\end{array}$ & 50 & $42 / 8$ & $\begin{array}{l}\text { PCR-RFLP } \\
\text { of TRAP-C2 }\end{array}$ & Sulaiman et al. unpub. data \\
\hline
\end{tabular}

Preliminary analysis of 65 pooled oyster samples using the SSU rRNA-based PCR-RFLP technique has shown the presence of Cryptosporidium oocysts in 26 samples. Twenty four of these positive samples were C. parvum, and each of the others was $C$. baileyi and $C$. serpentis. The majority of Cryptosporidium oocysts were of genotype 2 (22 samples), indicating animals maybe the most likely the source of most Cryptosporidium oocyst contamination in the Chesapeake Bay. Even though this is a highly populated area, only two samples had genotype 1 sequences. These results demonstrate that oysters can serve as a biologic monitor for Cryptosporidium oocyst contamination in waters. Because raw oysters are often consumed by humans, Cryptosporidium oocysts in oysters also pose a potential health concern. Other filter-feeders such as freshwater clams and marine mussels have also been shown to accumulate Cryptosporidium oocysts (Graczyk et al. 1998, Chalmers et al. 1997). They may serve as similar biologic monitors for Cryptosporidium oocyst contamination.

\section{CONCLUSIONS}

Although the traditional classification of species based on the vertebrate classes of their hosts is largely accurate, it has greatly underestimated the diversity various Cryptosporidium isolates. This has presented problems in the identification of parasites in environmental samples. Molecular tech- niques are now available to identify species of Cryptosporidium and to differentiate known genotypes of $C$. parvum, and should be very useful in the investigation of clinical outbreaks of cryptosporidiosis. The performance of these techniques in the analysis of environmental samples, however, has yet to be thoroughly demonstrated. Because of the nature of environmental samples, Cryptosporidium isolates from various hosts must be more extensively characterized before enough data have been acquired and interpreted to instill full confidence in the method.

\section{ACKNOWLEDGMENTS}

To Joself Limor for technical assistance.

\section{REFERENCES}

Awad-El-Kariem FA, Robinson HA, Dyson DA, Evans D, Wright S, Fox MT, McDonald V 1995. Differentiation between human and animal strains of Cryptosporidium parvum using isoenzyme typing. Parasitology 110: 129-132.

Awad-El-Kariem FA, Warhurst DC, McDonald V 1994. Detection of Cryptosporidium oocysts using a sytem based on PCR and endonuclease restriction. Parasitology 109: 19-22.

Bonnin A, Fourmaux MN, Dubremetz JF, Nelson RG, Gobet P, Harly G, Buisson M, Puygauthier-Toubas D, Gabriel-Pospisil F, Naciri M, Camerlynch P 1996. Genotyping human and bovine isolates of Cryptosporidium parvum by polymerase chain reaction-restriction fragment length polymorphism analysis of a repetitive DNA sequence. FEMS 
Microbiol Lett 137: 207-211.

Cai J, Collins MD, McDonald V, Thompson DE 1992. PCR cloning and nucleotide sequence determination of the 18S rRNA genes and internal transcribed spacer 1 of the protozoan parasites Cryptosporidium parvum and Cryptosporidium muris. Biochem Biophys Acta 1131: 317-320.

Carraway M, Widmer G, Tzipori S 1994. Genetic markers differentiate $C$. parvum isolates. $J$ Eukaryot Microbiol 41: 26S.

Carraway M, Tzipori S, Widmer G 1996. Identification of genetic heterogeneity in the Cryptosporidium parvum ribosomal repeat. Appl Env Microbiol 62: 712-716.

Carraway M, Tzipori S, Widmer G 1997. A new restriction fragment length polymorphism from Cryptosporidium parvum identifies genetically heterogeneous parasite populations and genotypic changes following transmission from bovine to human hosts. Infect Immun 65: 3958-3960.

Chalmers RM, Sturdee AP, Mellors P, Nicholson V, Lawlor F, Kenny F, Timpson P 1997. Cryptosporidium parvum in environmental samples in the Sligo area, Republic of Ireland: a preliminary report. Lett Appl Microbiol 25: 380-384.

Current WL, Upton SJ, Haynes TB 1986. The life cycle of Cryptosporidium baileyi n. sp. (Apicomplexa, Cryptosporidiidae) infecting chickens. J Protozool 33: 289-296.

Fayer R, Graczyk TK, Lewis EJ, Trout JM, Farley CA 1998. Survival of infectious Cryptosporidium parvum oocysts in seawater and eastern oysters (Crassostrea virginica) in the Chesapeake bay. Appl Environ Microbiol 64: 1070-1074.

Fayer R, Speer CA, Dubey JP 1997. The general biology of Cryptosporidium, p. 1-41. In R Fayer, Cryptosporidium and Cryptosporidiosis, CRC Press, Boca Raton, Florida.

Graczyk TK, Fayer R, Cranfield MR, Conn DB 1998. Recovery of waterborne Cryptosporidium parvum oocysts by freshwater benthic clams (Corbicula fluminea). Appl Environ Microbiol 64: 427-430.

Kilani RT, Wenman WM 1994. Geographical variation in 18S rDNA gene sequence of Cryptosporidium parvum. Int J Parasitol 24: 303-306.

Leng X, Mosier DA, Oberst RD 1996. Differentiation of Cryptosporidium parvum, C. muris, and C. baileyi by PCR-RFLP analysis of the $18 \mathrm{~s}$ rRNA gene. Vet Parasitol 62: 1-7.

Levine ND 1984. Taxonomy and review of the coccidian genus Cryptosporidium (Protozoa, Apicomplexa). J Protozool 31: 94-98.

Levine ND 1986. The taxonomy of Sarcocystis (Protozoa, Apicomplexa) species. J Parasitol 72: 372-382.

Mead JR, Humphreys RC, Sammons DW, Sterling C 1990. Isolation of isolate-specific sporozoite proteins of Cryptosporidium parvum by two-dimensional gel electrophoresis. Infect Immun 58: 2071-2075.

Morgan UM, Constantine CC, Forbes DA, Thompson RCA 1997. Differentiation between human and animal isolates of Cryptosporidium parvum using rDNA sequencing and direct PCR analysis. J Parasitol 83: 825-830.

Morgan UM, Constantine CC, O'Donoghue P, Meloni BP, O'Brien PA, Thompson RCA 1995. Molecular characterization of Cryptosporidium isolates from humans and other animals using random amplified polymorphic DNA analysis. Am J Trop Med Hyg 52: 559-564.

Nichols GL, McLauchlin J, Samuel D 1991. A technique for typing Cryptosporidium isolates. J Protozool 38 : 237S-240S.

Nina JMS, McDonald V, Dyson DA, Catchpole J, Uni S, Iseki M, Chiodini PL, McAdam KPWJ 1992. Analysis of oocyst wall and sporozoite antigens from three Cryptosporidium species. Infect Immun 60: 1509-1513.

O'Donoghue PJ 1995. Cryptosporidium and cryptosporidiosis in man and animals. Int J Parasitol 25: 139-195.

Ogunkolade BW, Robinson HA, McDonald V, Webster K, Evans DA 1993. Isoenzyme variation within the genus Cryptosporidium. Parasitol Res 79: 385-388.

Ortega YR, Sheehy RR, Cama VA, Oishi KK, Sterling CR 1991. Restriction fragment length polymorphism analysis of Cryptosporidium parvum isolates of bovine and human origin. J Protozool 38: 540-541.

Peng MP, Xiao L, Freeman AR, Arrowood MJ, Escalante A, Weltman AC, Ong C, Mac Kenzie WR, Lal AA, Beard CB 1997. Genetic polymorphism among Cryptosporidium parvum isolates supporting two distinct transmission cycle. sEmer Infect Dis 3: 1-9.

Spano F, Putignani L, McLauchlin J, Casemore DP, Crisanti A 1997. PCR-RFLP analysis of the Cryptosporidium oocyst wall protein (COWP) gene dicriminates between $C$. wrairi and $C$. parvum, and between $C$. parvum isolates of humand animal origin. FEMS Microbiol Lett 150: 209-217.

Tzipori S, Angus KW, Campbell I, Gray EW 1980. Cryptosporidium: evidence for a single-species genus. Infect Immun 30: 884-886.

Tzipori S, Griffiths JK 1998. Natural history and biology of Cryptosporidium parvum. Adv Parasitol 40: 5-36.

Upton SJ, Current WL 1985. The species of Cryptosporidium (Apicomplexa: Cryptosporidiidae) infecting mammals. J Parasitol 71: 625-9.

Vasquez JR, Gooze L, Kim K, Gut J, Petersen C, Nelson RG 1996. Potential antifolate resistance determinants and genotypic variation in the bifunctional dihydrofolate reductase-thymidylate synthase gene from human and bovine isolates of Cryptosporidium parvum. Mol Biochem Parasitol 79: 153-165. 
